\title{
Insulin-Like Growth Factor-I (IGF-I)/IGF-I Receptor Axis and Increased Invasion Activity of Fibroblasts in Keloid
}

\author{
AKIRa OHTSURU, Hiroshi YOSHIMOTO*, Hiroshi ISHIHARA*, HiroyUKi NAMBA AND \\ SHUNICHI YAMASHITA \\ Department of Nature Medicine, Atomic Bomb Disease Institute \\ * Department of Plastic and Reconstructive Surgery, Nagasaki University School of Medicine, Nagasaki 852-8523, Japan
}

\begin{abstract}
Activation of signals for insulin-like growth factor-I receptor (IGF-IR) is thought to be closely linked to abnormal cell proliferation and differentiation in various diseases. The keloid in which fibroblasts invade beyond the margins of the original wound, is a dermal fibroproliferative tissue of unknown etiology. Clinically, keloids are most commonly observed in subjects at ages between 10 and 30 years. Interestingly, plasma levels of growth hormone and IGF-I are also high during the same period, suggesting that IGF-I might be involved in the patho-physiology of keloid fibroblasts. We therefore first examined the expression level of IGF-IR in normal and keloid tissues. Immunohistochemical analysis confirmed increased expression of IGF-IR in keloid fibroblasts, but not in normal fibroblasts. On the other hand, the staining intensity of IGF-IR in the epidermis of normal tissues was almost equal to that in keloids. Next, to study the functional properties of the IGF-I/IGF-IR axis in both normal and keloid fibroblasts, we investigated invasion activities. The invasive activity of IGF-IR overexpressing keloid fibroblasts was greatly increased in the presence of IGF-I, and inhibited by a neutralizing antibody to IGF-I. In contrast, its activity of IGF-IR weak-expressing normal fibroblasts was not changed. Our results indicate the involvement of the activated IGF-I/IGF-IR axis in the pathogenesis of the invasive activity of fibroblasts.
\end{abstract}

Key words: IGF-I, IGF-I Receptor, Fibroblast

(Endocrine Journal 47: S41-S44, 2000)

KELOIDS are characterized by an abnormal dermal fibroproliferative reaction during wound healing after skin injury [1]. Previous studies showed that the response to certain growth factors, such as plateletderived growth factor (PDGF), epidermal growth factor (EGF) and fibroblast growth factor (FGF), differed in fibroblasts from keloid tissues compared to normal dermis. Haisa et al. [2] have demonstrated that stimulation by PDGF enhanced cell proliferation and migration of keloid fibroblasts compared to normal fibroblasts. The majority of these growth factors bind to receptors of the protein tyrosine kinase (PTK) family.

Correspondence to: Akira OHTSURU, M.D., Department of Nature Medicine, Atomic Bomb Disease Institute, Nagasaki University School of Medicine, 1-12-4 Sakamoto, Nagasaki 852-8523, Japan
PTKs play a central role in the regulation of growth and differentiation of eukaryotic cells as components of the signal transduction pathway. Since more than 100 different PTKs have been cloned, it would be difficult to identify the exact PTK involved in keloid formation. To solve this problem, we previously applied the PCR-based cloning technique with a degenerated primer, and compared the expression profile of receptor-type PTKs in primary culture of fibroblasts derived from both normal dermis and keloids [3]. In this previous experiment, we have demonstrated that IGF-IR clones were overexpressed only keloid derived-fibroblasts. In the present study, we therefore, focused on the expression and function of IGF-IR in keloid fibroblasts compared to adjacent normal fibroblasts.

In addition to cell proliferation and differentiation function, activated PTKs signals are closely related to 
malignant phenotypes such as invasion. Although keloid is a benign disorder, it is invasive beyond the margins of the original wound [1]. We speculated that the invasion activity of keloid fibroblasts is similar to some extent to that of malignant cells. To analyze the function of keloid specific IGF-IR signal, we used an invasion assay system usually used to estimate the invasive potential of malignant cells.

\section{Materials and Methods}

The three keloid samples used in this investigation were obtained from three different Japanese female patients after undergoing surgical excision. We also established primary cultures of fibroblasts taken from keloid and normal skin around the keloid. Informed consent was obtained from each subject. Total RNAs were extracted from normal and keloid fibroblasts of the same patient by a modified acid /guanidine thiocyanate/phenol/chloroform method.

All collected tissues were stained immunohistochemically. Sections were later incubated with an optimal dilution $(1.0 \mu \mathrm{g} / \mathrm{ml})$ of a primary antibody to IGF-IR (rabbit polyclonal antibody for the $\beta$-subunits of human IGF-IR; Santa Cruz Biotechnology, Inc., Santa Cruz, CA). Slides were sequentially incubated with biotinated goat antirabbit immunoglobulin antibodies and the avidinbiotin complex. After the addition of $0.05 \%$ 3,3'diaminobenzidine tetrahydrochloride, the slides were flooded with Tris-EDTA buffer, dehydrated and mounted. Negative controls were prepared with the same serial sections but replacing the primary antibody with non-immunized serum. mRNA level expression of IGF-IR was confirmed by RT-PCR.

Normal fibroblasts were seeded at $1 \times 10^{3}$ cells/well into 24-well plates and cultured in DMEM containing $10 \%$ FBS for 2 days. The medium was changed to serum-free DMEM/F10, and membrane culture inserts, $12 \mu \mathrm{m}$ pore size, (Iwaki Glass Co., Chiba, Japan) were placed in 24-well plates. Cell matrix (type IA collagen, Nitta Zeratin Co., Osaka), $10 \times \mathrm{F} 10$, and buffer were mixed of a volume rate of $8: 1: 1$. Gel mixture $(50 \mu \mathrm{l})$ was applied to each chamber, and incubated for one hour. Normal and keloid fibroblasts $\left(2.0 \times 10^{3}\right.$ cells/well), suspended in serum-free DMEM/F10, were added to the upper chamber. IGF-I $(100 \mathrm{ng} / \mathrm{ml})$ and $2 \%$ FBS was added to the chamber after 3,24 and 48 hours of incubation. The culture continued for 72 hours. The IGF-IR expression was confirmed by western blotting using above antibody. In another experiment, keloid fibroblasts $\left(2.0 \times 10^{3}\right.$ cells/well), suspended in serum-free DMEM/F10, were then added to the upper chamber. Antibody to IGF-IR (1H7) $(10 \mathrm{nM}$, mouse monoclonal antibody for human IGF-IR, Santa Cruz Biotechnology) was added to the chamber after 3, 24 and 48 hours of incubation, and 2\% FBS was added to the chamber after 4, 25 and 49 hours of incubation. At the end of the incubation period, the cells on the upper surface of the filter were completely removed by wiping with a cotton swab. The chambers were fixed in 70\% ethanol and stained with hematoxylin and eosin. Cells on the lower surface were photographed and counted.

\section{Results}

To confirm IGF-IR expression, we performed western blotting studies with anti-IGF-IR antibody in cultured fibroblasts. No clear stainingband was present in normal cultured fibroblasts, but in contrast, positive $95 \mathrm{kDa}$ band of mature form IGF-IR $\beta$-subunit was evident in cultured keloid fibroblasts (data not shown). Histological examination of the dermis showed that the keloid contained numerous blood vessels and collagen fibers compared to normal skin. Immunohistochemistry for the IGF-IR $\beta$ subunit showed that the staining intensity in the epidermis and endothelial cells of normal specimens was almost similar to that of keloids. Staining for IGF-IR was detected in fibroblasts of the keloid specimens, but not in normal skin specimens (Table 1). RT-PCR analysis also showed that IGFIR mRNA was overexpressing in fibroblast primary culture of keloid compared to that of normal (data not shown).

To elucidate the functional effects of IGF-I on cell invasion, normal and keloid fibroblasts were cultured in medium containing $0 \%, 2 \%$ FBS, or IGF-I $(100 \mathrm{ng} / \mathrm{ml})$. The presence of IGF-I or FBS in the culture medium significantly increased the number of invading keloid fibroblasts compared with keloid fibroblasts in serum-free medium and normal fibroblasts. When fibroblasts were not inoculated in the lower chamber, invasion was completely suppressed. 
Table 1. IGF-IR expression of keloid fibroblasts and normal control fibroblasts in immunohistochemical staining.

\begin{tabular}{ccccc}
\hline \multirow{2}{*}{ Subject } & Sex & $\begin{array}{c}\text { Age } \\
\text { (years) }\end{array}$ & \multicolumn{2}{c}{ IGF-IR exprssion } \\
\cline { 4 - 5 } & & & Epidermis & Subcutaneous fibroblasts \\
\hline Keloid & & & & \\
1 & F & 18 & + & ++ \\
2 & F & 73 & + & ++ \\
3 & F & 46 & + & ++ \\
Control & & & & - \\
4 & M & 30 & + & - \\
5 & M & 50 & + & - \\
6 & M & 5 & + & - \\
$7 *$ & F & 18 & + & + \\
\hline
\end{tabular}

*This sample was obtained from normal skin of No. 1 patient.

IGF-IR expression is indicated as below, ++ : strong positive, + : positive, - : negative

This phenomenon suggests that growth factor including IGF-I produced by normal fibroblasts stimulated keloid fibroblasts migration and invasion. To study how IGF-I influences the invasion activity of keloid fibroblasts in the presence of FBS, we blocked the effect of IGF-I by using a neutralizing antibody against IGF-IR. The antibody inhibited FBS-induced stimulation of invasion of keloid (Table 2). In contrast, no inhibitory effect was obserbed by nonimmune IgG as a negative control.

Table 2. Invasive activity of fibroblasts under the various condition

\begin{tabular}{lc}
\hline & $\%$ Change in Invasion \\
\hline Normal & \\
IGF-I $100 \mathrm{ng} / \mathrm{ml}$ & $9 \% \pm 35 \%$ \\
$2 \%$ FBS & $22 \% \pm 45 \%$ \\
Keloid & $140 \% \pm 63 \% *$ \\
IGF-I $100 \mathrm{ng} / \mathrm{ml}$ & $254 \% \pm 55 \% * *$ \\
$2 \%$ FBS & $63 \% \pm 39 \%^{* * *}$ \\
$2 \%$ FBS + Anti IGF-IR &
\end{tabular}

$\%$ Change in Invasion was standardized by the invasive cell number in the serum free condition (serum free as a control). The $\%$ of invasive fibroblasts increased in keloid in the presence of IGF-I $(100 \mathrm{ng} / \mathrm{ml})$ or $2 \%$ FBS. ${ }^{*} \mathrm{p}<0.03$, ${ }^{* *} \mathrm{p}<0.01$. Treatment with a neutralizing antibody to IGF-IR reduced the number of invasive cells in the presence of $2 \%$ FBS. $* * * \mathrm{p}<0.03$.

\section{Discussion}

Insulin-like growth factors are peptides that are structurally similar to proinsulin. IGF-I mediates various actions of the growth hormone postnatally and is thought to have a dual function, acting both as a mitogen and a differentiation factor. In addition, several studies have suggested that IGF-I production is increased in various types of regenerating tissue including subcutaneous tissue after injury. Increased expression of IGF-I mRNA has been reported in hypertrophic scar tissue. Furthermore, IGF-I reduced collagenase production by post-burn hypertrophic scar fibroblasts compared to normal fibroblast. In keloid fibroblasts, IGF-I may alter the process regulating the synthesis of extracellular matrix. Keloids are collagenous lesions acquired as a result of delayed wound healing. Other studies have demonstrated increased expression of IGF-I during the later stages of wound healing. The IGF-I/IGFIR pathway may delay the wound healing process and promote keloid formation.

Activation of the IGF-IR by its ligands (IGF-I, IGF-II and insulin) plays an important role in the control of cell growth and malignant transformation and is an important inhibitor of apoptosis. Experiments with dominant negative mutants of IGF-IR, antibodies to IGF-IR, or antisense strategies directed against IGF-IR mRNA have shown that reduced or aberrant receptor expression is associated with a reversal of the transformed phenotype, with prevention of metastasis and induction of apoptosis. Furthermore, cells lacking IGF-IR have prolonged cell cycle kinetics, and IGF-IR-deficient mice have severely diminished growth.

How does the signaling pathway of the IGF-IR influence keloid formation? To examine the functional properties of the IGF-I/IGF-IR pathway, we investigated cell proliferation and invasion in the presence of exogenous IGF-I or neutralizing antibody against IGF-I. Previous our data have shown that the mitogenic effect of IGF-I on both normal and keloid fibroblasts was very weak compared to serum stimulation [3]. In contrast, the invasive activity of IGF-IR overexpressing keloid fibroblasts was markedly increased in the presence of IGF-I, and inhibited by a neutralizing antibody against IGF-I. In another study, mouse fibroblasts that overexpress 
IGF-IR were found to have reduced growth factor requirements in vitro and were less susceptible to apoptosis. In our preliminary studies, keloid-derived fibroblasts have obtained the increased resistancy against ceramide-induced apoptosis by IGF-I (unpublished data). Combined together, our results and those of other investigators suggest that an abnormal activation of IGF-I/IGF-IR axis may influence to pathological action of fibroblasts in keloid or some other diseases, although the further mechanism remains to be clarified.

\section{References}

1. Tredget EE, Nedelec B, Scott PG, Ghahary A: Hypertrophic scars, keloids, and contractures. The cellular and molecular basis for therapy. [Review]. (1997) Surg Clin North Am 77: 701-730.

2. Haisa M, Okochi H, Grotendorst GR (1994) Elevated levels of PDGF alpha receptors in keloid fibroblasts contribute to an enhanced response to PDGF. $J$
Invest Dermatol 103: 560-563.

3. Yoshimoto $\mathrm{H}$, Ishihara $\mathrm{H}$, Ohtsuru A, Akino $\mathrm{K}$, Murakami R, Kuroda H, Namba H, Ito M, Fujii T, Yamashita $S$ (1999) Overexpression of insulin-like growth factor-1 (IGF-I) receptor and the invasiveness of cultured keloid fibroblasts. Am J Pathol 154: 883889. 